\title{
O lugar da experiência do adoecimento no entendimento da doença: discurso médico e subjetividade
}

\author{
The place of the experience of illness in the understanding \\ of ailments: medical discourse and subjectivity
}

Amanda Barros Pereira Palmeira ${ }^{1}$

Rodrigo Barros Gewehr ${ }^{1}$

\footnotetext{
${ }^{1}$ Universidade Federal de Alagoas. Av. Lourival Melo Mota, Tabuleiro dos Martins. 57072-970

Maceio AL Brasil.

maddyxpp@gmail.com
}

\begin{abstract}
Recent discussions in medical discourse seek to demonstrate the apparent progressive omission of the subject as well as the notion of subjectivity in the development of modern medicine, both in its foundations in clinical practice and in its basic theoretical framework. As a result, they reveal that medicine has evolved in the understanding of the ailment, while still leaving a blind spot regarding the experience of suffering. In terms of a reaction countless attempts to restore subjectivity in the therapeutic process and medical discourse were have been conducted, aiming at comprehensive and humanized care through what might be called exteriority discourse. Using Jung's analytical psychology as a benchmark, the experience of suffering and its consequences are present in clinical practice as expressions of subjectivity in the theoretical and practical fields.
\end{abstract}

Key words Comprehensiveness in health, Science, Physician-patient relations, Psychology, Clinical medicine
Resumo Discussões recentes acerca do discurso médico buscam demonstrar o aparente esquecimento progressivo do sujeito, assim como da noção de subjetividade, no desenvolvimento da medicina moderna, tanto em seus fundamentos na prática clínica quanto em seu corpo teórico de base. Com isso, mostram que a Medicina evoluiu no entendimento da doença, embora ainda mantenha a experiencia do sofrimento como ponto cego. Como reação, são realizadas inúmeras tentativas de restituir a subjetividade no processo terapêutico e no discurso médico, buscando um cuidado integral e humanizado através do que podemos considerar como discursos de exterioridade. Tendo por referencial a Psicologia Analítica de Jung, analisamos como a experiência do sofrimento e seus desdobramentos estão presentes na prática clínica, como expressão de subjetividade, nos campos teórico e prático.

Palavras-chave Integralidade em saúde, Ciência, Relação médico-paciente, Psicologia, Clinnica médica 


\section{Introdução}

A prática clínica, enquanto objeto de estudo, é fonte incessante de inquietações e pesquisas que visam a melhor compreensão dos processos de adoecimento e cura, o aperfeiçoamento de procedimentos e consequentemente da atenção prestada à população. As considerações aqui realizadas possuem como plano de fundo a prática clínica, como parte de um programa de Residência Multiprofissional em hospital universitário. Nesse sentido, partimos de um campo polifônico e que causa estranhamentos diversos. Embora a prática clínica seja ampla e complexa, no que diz respeito ao ambiente hospitalar, ela ainda é orientada pela atuação médica. Se adicionarmos a isso a presença do hospital ao longo da formação dos profissionais de saúde, podemos observar alguns elementos-chave de como se pensa a prática clínica, suas potencialidades e seus limites, sobretudo quando considerada apenas a partir do ponto de vista do modelo biomédico. O lugar atribuído à subjetividade neste ambiente servirá, por sua vez, como elemento de observação dos aspectos mais estruturais que se fixaram no modelo de saúde atual. Partindo do ponto de vista da inserção da Psicologia neste contexto, este ensaio problematiza a prática clínica e a centralidade do modelo biomédico tal qual nossa experiência nos permitiu visualizá-los. A partir disso, e ao trabalhar diretamente com as demandas de profissionais de saúde, propomos a discussão sobre as relações estabelecidas na clínica como desafios à implementação da integralidade em saúde e possíveis entraves na visão do sujeito como um todo.

Isso depende, todavia, de uma revisão dos fundamentos epistemológicos que norteiam a prática, pois além de dificuldades que poderiam ser atribuídas a questões estruturais ou contextuais, a própria perspectiva dos processos de adoecimento e cura interferem no modo como nos dirigimos aos pacientes e usuários dos serviços de saúde. Neste plano de interrogação, as soluções possíveis, se não podem prescindir da luta por condições adequadas de trabalho, dependem também da transformação de postura e de compreensão diante das demandas por parte de pessoas em sofrimento. A contribuição da psicologia clínica nos servirá como base de reflexão, sem desconsiderarmos que a atenção à saúde é um sistema complexo, que envolve múltiplas abordagens e a necessidade de permanente reflexão, em vários eixos que vão das políticas públicas, passando pelas condições de trabalho e chegando também ao plano epistemológico, que é nosso foco de debate neste ensaio. A opção que fazemos por enfatizar o fator psicológico nesse quadro complexo tem como objetivo ressaltar o lugar da subjetividade nessa problemática, e também sugerir que a inclusão dessa dimensão é primordial para avançarmos na ideia de atenção integral à saúde.

Apesar das discussões sobre humanização, o lugar da subjetividade, principalmente na instituição hospitalar, é o de exceção. Com isso, o psicólogo é convidado a agir para complementar a prática médica, o que não significa necessariamente dar lugar à subjetividade do paciente. Por outro lado, o médico, respaldado por sua cientificidade, assume o papel de imparcial e objetivo.

Dentre as possibilidades de reconhecimento dos efeitos da subjetividade, podemos enunciar a não adesão ao tratamento, a crença na cura, e até o choro. Nesse sentido, o discurso do paciente, como tentativa de contextualização do adoecimento, pode representar a resistência à supressão da subjetividade. Na prática clínica, é comum que surja a demanda profissional referente ao "entendimento da doença", a partir da qual se supõe que o paciente é incapaz de compreender todos os aspectos contidos em seu diagnóstico. Contudo, a escuta clínica permite entrever que a preocupação com a falta de entendimento do paciente pode corresponder à paralização do médico ou da equipe frente à subjetividade. Diante dessas manifestações mais ou menos evidentes da subjetividade, mais ou menos em acordo com as propostas terapêuticas, cabe interrogar o que está sendo expresso nessas demandas, como se manifestam em pacientes e nos profissionais e as condições de acolhimento de demandas dirigidas à equipe de saúde.

\section{Entre a compreensão da patologia e a experiência do adoecimento}

Uma das noções para pensar a clínica é a patologia, a qual perpassa diversas finalidades terapêuticas e discursos e segue sendo, como aponta Canguilhem ${ }^{1}$, fundamental para a atividade clínica. Dessa forma, a compreensão da patologia embasa a prática e está contida em uma estruturação específica do saber. Para Tesser e Luz², "as patologias não só ganharam centralidade teórica e metodológica (...) como sofreram um processo de ontologização que lhes imprimiu existência independente no ideário biomédico". Por outro lado, há na posição de Canguilhem a demanda pela reintegração desse fator independente, que pode ser pensada a partir de um sujeito e dos 
desdobramentos inclusos na apreciação da experiência do adoecimento. Ou seja, trata-se aqui de refletir sobre o lugar da compreensão da patologia e da experiência do adoecimento, por si mesmas necessariamente relacionadas e no cerne da sustentação de todas as práticas clínicas.

Apesar de a doença reter o caráter de entidade quase independente que acomete alguém e modifica sua existência ${ }^{1}$, há ainda um efeito estrutural do adoecimento na necessidade de se compreender tal experiência. Segundo Nascimento et al. ${ }^{3}$, é possível identificar diferentes sistemas de pensamento dentro da Medicina que auxiliam a refletir acerca da racionalidade médica; reunindo noções de anatomia e fisiologia, saúde e doença, padrões de diagnóstico e direcionamento de intervenção terapêutica, além de um referencial filosófico de base. Dentre esses sistemas, destaca-se o paradigma biomédico, o qual "enfatiza concepções (...) centradas na doença e no controle do corpo biológico e social, compatíveis com a visão de controle sobre a natureza"3. Do ponto de vista epistemológico, isso traduz a equivalência entre real e racional, e a Medicina ainda está grandemente inserida nesse paradigma.

As críticas voltadas ao aspecto político e social da Medicina e o movimento que questiona sua base epistemológica parecem apontar alguma insuficiência nesse paradigma. Na ênfase ao fisiológico, a prática médica acentua a cisão entre corpo e psiquismo, e o caráter impositivo de sua normatividade ameaça a apropriação do adoecimento por parte do indivíduo. Ambos os casos se opõem às demandas sociais e à perspectiva de saúde atuais.

A Psicologia clínica mostrou que o paciente tinha algo a dizer sobre seu sofrimento, que a ação tecnológica baseada na biologia pode ser insuficiente para alcançar a cura, e que há um componente psíquico a ser reconhecido no adoecimento. Adentramos, assim, no plano de interrogação que diz respeito à expressão e à experiência do sofrimento. Se a ciência médica destaca a neutralidade, a clínica tem que lidar com o sujeito por imposição prática. Mesmo que somente nos casos onde o tratamento não se mostra adequado, o doente ganha voz, e os problemas começam quando há dissonância entre a fala do paciente e a fala do médico. Mais uma vez, o corpo de conhecimento da medicina é posto em questão pelo reconhecimento da distância entre a experiência do sofrimento e o conhecimento da patologia.

Tomando como exemplo o frequente questionamento da prática médica em comparação com a crescente busca por práticas complemen- tares e alternativas, consideramos que, ao invés de tratar a fala do paciente como incorreta, faz-se necessário reconhecer sua presença como integrante do processo de adoecimento e cura.

Isto pode ser evidência de quanto a presença de fatores subjetivos é geradora de incômodo e rupturas dentro da dinâmica do tratamento. Diferentes perspectivas em relação ao lugar da subjetividade nos processos de adoecimento e cura podem conduzir a distintos direcionamentos terapêuticos, o que pode levar a incomunicabilidades entre áreas envolvidas na atenção à saúde. A inclusão desses fatores é o que nos levaria a uma sistematização integral de saúde, pela problematização das implicações de tal abertura e do afastamento que ela pode suscitar entre práticas diversas. A partir dessa análise de rupturas e distanciamentos é que se pode pensar em refazer o caminho do diálogo interdisciplinar, que é condição fundamental para que os serviços prestados na área da saúde possam estar mais em sintonia com as pessoas que demandam atenção.

\section{O enfoque na patologia}

Ao pensar as áreas de atuação em saúde, o desenvolvimento e a constante atualização do conhecimento possuem o objetivo de aumentar a eficácia terapêutica. $\mathrm{O}$ dado biológico é justificado em sua validação terapêutica. O núcleo central de atividade terapêutica da Medicina concentra-se na intervenção tecnológica:

a tendência metodológica a decompor o objeto em elementos, a comparar esses elementos em si e ordená-los em uma totalidade racionalmente montada e hierarquicamente recomposta, permanece dominante na base da maioria das disciplinas, sobretudo nos grandes ramos das ciências mais próximas da vida humana: a biologia e a medicina, ou melhor, uma certa medicina racionalista $e$ mecanicista ${ }^{4}$.

Essas características permitem pensar a saúde e a doença em termos naturais, com base no estudo de diversos sistemas. De forma complementar, conta-se com um sistema classificatório, baseado no agrupamento de características patológicas. Para Fonseca e Stauffer ${ }^{4}$ há correlação entre a utilização do referencial mecanicista e o desenvolvimento de modelos classificatórios. Quer dizer:

[...] a patologia detém sobre a prática clínica a liderança da teoria e o privilégio da ciência sobre a arte, obtendo-se, dessa forma, uma dupla objetivação: do corpo humano, que se torna a 'sede das doenças', e das doenças que se tornam 'entidades patológicas's. 
Segundo Guerra ${ }^{6}$, adotando o pensamento de Canguilhem, a prática médica é resultado de um conhecimento que possui, ao mesmo tempo, aspectos tecnológicos e antropológicos. A centralidade na patologia, todavia, significou o rompimento com aspectos doravante relegados à metafísica - como a própria noção de cura - face à necessidade de desenvolvimento tecnológico do saber médico. Outrossim, a ênfase tecnológica dentro de uma base biológica do conhecimento parece provocar a transição do fator humano para um segundo plano, reapropriado inicialmente sob a forma de individualidade orgânica.

Contudo, apesar de críticas, é inegável o avanço e a precisão conquistados através do enfoque no entendimento da patologia. O corpo é constituído como realidade biológica e, no cenário da prática médica, mais que em qualquer outra área, a precisão e o manejo da técnica fazem toda a diferença. Por isso, como aponta Canguilhem ${ }^{1}$ :

Não se trata absolutamente de dispensar os médicos de estudar a fisiologia e a farmacodinâmica. É muito importante não confundir a doença com o pecado nem com o demônio. Mas só porque o mal não é um ser não se deve concluir que seja um conceito desprovido de sentido, ou que não existam valores negativos, mesmo entre os valores vitais; não se pode concluir que, no fundo, o estado patológico não seja nada mais que o estado normal.

Com isso, queremos dizer que o desenvolvimento das ciências que embasam a Medicina determinou seu enfoque patológico. Isso significou, ao mesmo tempo, um avanço no conhecimento e na aplicabilidade terapêutica. Diante de tal formação, o médico prioriza elementos que possibilitem a classificação nosográfica dos sintomas apresentados pelo paciente. A seu modo, busca dar sentido à patologia e falha ao marginalizar, por exigência epistemológica, o que não é passível de objetivação.

$\mathrm{O}$ enfoque patológico significa uma leitura condizente ao conhecimento médico atual, que narra a doença com base no que foi e no que se espera ser observado em cada etapa do tratamento e do desenvolvimento típico de cada patologia. A exemplo do exposto por Canguilhem na citação acima, entretanto, nisso parece haver alguma sutileza no modo em como o médico e outros profissionais da saúde mostram relutância em enxergar que outras perspectivas - inclusive a do próprio paciente - não são conceitos desprovidos de sentido.

\section{A fundamentação da escuta da experiência do adoecimento}

O paciente, inicialmente inserido no tratamento por meio de uma escuta com o objetivo de colher informações que auxiliem o desenrolar do trabalho clínico, retorna no discurso médico representado pela patologia e é, desse modo, forçado ao anonimato ${ }^{7}$. Neste espaço, há sempre a tendência a pensar a escuta como questão ética mais que técnica. Por outro lado, da mesma forma como apontado por Dunker e Kyrillos Neto ${ }^{8}$ e Nader ${ }^{9}$ em relação aos novos modelos de atenção à saúde mental, o enfoque social das políticas públicas, criticando as relações de poder estabelecidas e o caráter prescritivo do saber médico, corre o risco de produzir novas formas de normatividade, às quais é fundamental estar atento. Supõe-se estabelecer as melhores condições para o "usuário", embora isso seja de fato bastante relativo e não esteja livre de ser uma imposição a mais, como a palavra do médico. Assim, humanizar o atendimento não é sinônimo de incluir a experiência subjetiva do adoecimento no processo terapêutico.

A exigência por evidências e cientificidade nos faz abdicar de nossos próprios insights e intuições como inapropriados ${ }^{10}$. Por isso, a presença da subjetividade do paciente pode provocar incômodo e levar ao questionamento do conhecimento que age sobre ele; quer o referido conhecimento seja a Psicologia, as ciências sociais que sustentam a formulação de Políticas Públicas, ou o conhecimento médico. Como, então, podemos escutar o paciente tomando sua experiência do adoecimento como componente integral e técnico do processo terapêutico?

Para além da Psicologia, pode-se pensar que o próprio ato de falar é suficiente para que o enfermo possa sentir-se melhor e aderir ao tratamento prescrito. É também possível pensar que os médicos devem aprender a ouvir seus pacientes, como forma de estreitar a distância que os separa diante da ignorância de um e da detenção do poder de conhecimento do outro. Contudo, apesar das possibilidades intrínsecas em cada um desses posicionamentos, podemos argumentar que o primeiro não constitui uma escuta de fato e que o segundo precisa ainda reconhecer o fator psíquico presente no vínculo com o médico ou outro profissional da saúde ${ }^{6}$.

Seguindo esta lógica, a subjetividade é reconhecida como direito, e a escuta como questão moral e ética para reflexão do profissional. $\mathrm{Na}$ prática atual do SUS, isto pode ser traduzido nos incentivos à educação em saúde e na preocupa- 
ção dos profissionais quanto ao entendimento e nível de informação possuídos pelo paciente. Ainda assim, tais medidas são incapazes de superar o status de concessão que assumem, jamais conseguindo justificar-se dentro do corpo do saber técnico e científico.

Podemos então considerar as diferentes possibilidades de inserção da escuta da experiência do paciente. Os aspectos decorrentes do "saber clínico" do paciente, bem como sua integração com referencial teórico da clínica, não são considerados conhecimento científico. Assim, as iniciativas até então citadas não conseguem ultrapassar a prática e alcançar o saber médico na dimensão epistemológica de seu conhecimento científico. Exigências por empatia, humanização e subjetivação assumem uma posição frágil. Dentro deste raciocínio, a Medicina - com a predominância da objetividade biomédica - vê como apenas acessória a visão da necessidade de sensibilização do médico, pois que esta estaria baseada apenas em padrões morais, na atenção ao paciente, e não em prerrogativas científicas.

Se objetivamos de fato captar a estrutura epistêmica da Medicina, incluindo o conjunto de conhecimentos relegados, de forma indiferenciada, à arte médica, então este objetivo motiva uma nova abordagem a um desafio ao dualismo epistemológico da Medicina ${ }^{11}$.

O estabelecimento do dualismo entre a prática clínica e o conhecimento científico está baseado em um ideal de objetividade científica. Já a tentativa de incluir a subjetividade como algo mais que atributo particular à prática impõe uma crítica à estrutura epistemológica da Medicina como a conhecemos hoje. Por isso, a fundamentação da escuta clínica da experiência do paciente deve perpassar ambos os aspectos. O reconhecimento da necessidade de ajustes éticos, morais e sociais, mostra-se insuficiente do ponto de vista epistemológico, o que influi diretamente na prática subsequente. Ao permanecer nessa dicotomia, a prática reproduz e perpetua a oposição entre objetividade e subjetividade, resultando na exclusão da última quando tomadas como contrapontos absolutos. Essa oposição radical acaba alimentando a visão ingênua da objetividade necessária e suficiente do profissional.

De início, poderíamos estar inclinados a concordar com a lógica médica tradicional e questionar a importância de falar em subjetividade, e principalmente em compreensão do adoecimento, ao nos depararmos com casos de lesão ou patologia orgânica. Se alguém quebra o braço, cabe ao médico simplesmente fazer com que este retome sua funcionalidade. Mesmo que haja uma leitura psicológica dos eventos que levaram ao acontecimento, isso não muda o fato concreto de que o braço precisa ser consertado. Portanto, colocamos em questão não a atribuição de uma psicogênese, mas o reconhecimento de que mesmo um braço quebrado ativará processos concorrentes no sistema psíquico. Isso implica dizer que a subjetividade está lá, participando do processo de adoecimento e de cura, seja este fato reconhecido ou não, incluso ou não na terapêutica.

Parece importante ressaltar que a crítica realizada pela inserção da subjetividade do paciente - e do médico - não avança em sua base epistemológica, visto que não há reconhecimento do discurso do paciente pelo discurso biomédico. $\mathrm{O}$ reconhecimento da condição de sujeito e a legitimidade de seu discurso parecem conquistas distintas nesse caso.

\section{Jung e a prática clínica}

Uma das queixas à Medicina concerne sua impessoalidade, a partir da qual se presume ser suficientemente objetiva para avaliar as necessidades de intervenção terapêutica. A supressão da subjetividade é consequência de um ideal de generalização o qual, em nossa sociedade, é adquirido somente através da aplicação do conhecimento científico. Seguindo outro viés, Jung ${ }^{12}$ exemplifica uma das características do processo de cura no Antigo Egito, ao dizer que “(...) na medicina antiga era largamente conhecido que, transportando-se uma doença pessoal a um nível mais alto e impessoal, atingia-se um efeito curativo". Através da narrativa mitológica, o paciente era conduzido a um movimento de cura. Por mais que esse grau de identificação tenha sido abandonado, a generalização permanece presente na construção do conhecimento biológico e "a habilidade de empregar um ponto de vista geral é de grande valor terapêutico"12. Podemos observar que, apesar de reter seu papel no processo de cura, o deslocamento da generalização instituída como a priori objetivo, e não mais por seu potencial unificador junto ao inconsciente, pode produzir o efeito oposto em termos de valor terapêutico. Ou seja, enquanto a generalização no nível simbólico é embasada por seus efeitos objetivos na experiência que o paciente tem de seu padecimento, as generalizações em termos de abstração científica parecem não produzir os mesmos efeitos no polo da experiência do adoecimento, ainda que sejam mais eficazes em termos de precisão e procedimentos. 
$\mathrm{Na}$ dicotomia criada entre ciência médica e clínica médica, a prática foi sendo dominada pela técnica - como aplicação de um saber, dando especial ênfase ao diagnóstico e ao conhecimento acerca de doenças. Em contrapartida, a crescente busca por práticas complementares e alternativas retoma a importância da relação estabelecida entre paciente e médico, em sua dimensão simbólica.

Não se pode mais entender a doença como um ens per se, como uma coisa desenraizada, como há algum tempo atrás se julgava que fosse. A medicina moderna, a clínica geral, por exemplo, concebe a doença como um sistema composto de fatores prejudiciais, e de elementos que levam à cura ${ }^{12}$.

Por outro lado, "a doença faz o homem mais corporal, torna-o corpo e nada mais"13. A princípio, essas palavras podem ser tomadas como justificativa para a exclusão da subjetividade. Todavia, em um contexto ampliado, também podem ser pensadas como a afirmação da experiência do adoecimento e do discurso do paciente. Se, enfermo, o ser humano é nada mais que um corpo doente, isto garante sua total inserção na concretude da doença. Com isso, é sua vivência que intuitivamente norteia seu conhecimento sobre a patologia, mais que qualquer tentativa de medicalização via informação de conhecimento científico. Ou seja, "alegações de medicalização subestimam a habilidade de resistir a ideias médicas e ainda contar com o próprio conhecimento e experiência" ${ }^{10}$. Jackie Pigeaud ${ }^{14}$ acrescenta, nesse sentido, um aspecto importante. Diz o autor que independentemente de a doença ser realidade ou ilusão, existe uma realidade do sofrimento, "ainda que se trate de uma realidade do imaginário. A ilusão faz sofrer tanto quanto". É nesse interseção entre real e imaginário que o saber médico acaba calando, ou atribuindo tão somente um valor ético à dimensão da subjetividade, o que desconsidera o aspecto epistemológico da estrutura do adoecimento. Se há necessidade de se considerar o ser humano integralmente, essa dimensão não pode ser excluída da razão terapêutica, sob pena de reduzirmos o alcance do potencial terapêutico.

Jung $^{15}$ distingue Psicoterapia e Medicina, e afirma que, na Psicoterapia, a personalidade do psicoterapeuta constitui o fator principal para a cura. Enquanto aplicar a mesma lógica à prática médica em geral pode mostrar-se uma empreitada precipitada, o conflito entre prática clínica e conhecimento científico, dentro da Medicina, pode ser tomado como evidência para refletir sobre as implicações da máxima Ars requirit to- tum hominem [a arte requer o homem inteiro]. Jung insiste na totalidade do terapeuta em contraposição ao dogmatismo atribuído à aplicação automática da teoria, através do posicionamento de que o "o uso de teorias deve ser evitado, exceto como auxiliar. A partir do momento em que viram dogma, é evidente que alguma dúvida interior está sendo suprimida" ${ }^{15}$. Em termos de referencial teórico, essas afirmações não conseguem sustentação no conhecimento biomédico da Medicina, estão em oposição a seus principais fundamentos. Do ponto de vista psicológico, contudo, esse mecanismo se repete a cada intervenção médica.

Por tradição, o objeto principal da Medicina corresponde ao corpo mais que à psique - sendo esta considerada apenas mais um fator biológico - no qual o homem aparece na qualidade de fenômeno fisiológico e anatômico. Assim, pouco se fala sobre fatores intermediários entre a construção do conhecimento científico e sua aplicação na prática clínica. Idealmente, caberia ao médico simplesmente dispor da tecnologia mais avançada e do conhecimento mais atual, e isso seria o suficiente. Ao contrário da ideia de Jung que aponta a personalidade do terapeuta como fator fundamental para a cura, na Medicina a eficácia está na apropriação integral do conhecimento já produzido.

Opondo-se a isto, Guerra ${ }^{6}$ pontua o desejo de curar e conhecer como marcantes na prática e inerentes à atuação do profissional. Considerando as ideias expostas acima, todavia, o não reconhecimento desses aspectos posiciona-os entre os conteúdos que permanecem negligenciados, embora presentes, inadvertidamente, na relação formada no contato com o paciente. Seguindo a perspectiva junguiana ${ }^{14} \mathrm{e}$ a dinâmica de funcionamento da psique que ela propõe, isto implica a necessidade de reconhecer os processos psíquicos que se manifestam espontaneamente durante o tratamento. Ou seja, o relacionamento estabelecido entre médico e paciente, enquanto relação profissional e humana, pode ilustrar e reproduzir uma tendência à unilateralidade do sistema psíquico, na qual alguns conteúdos permanecem inconscientes. A evitação sistemática do saber inerente à experiência do adoecimento é algo que pode excluir aspectos sutis dos quadros patológicos, tais como adoecimentos recorrentes, adesão ao tratamento, maior ou menor resposta às terapêuticas, bem como aspectos relacionados à maior ou menor disposição dos profissionais com este ou aquele paciente, com esta ou aquela técnica terapêutica, com as próprias ansiedades 
relacionadas ao adoecimento, às possibilidades de tratamento e à morte. Sendo assim, a Medicina admite e mesmo requer a inclusão da subjetividade ${ }^{6}$.

Se o discurso biomédico, enquanto sistematização do pensamento, reproduz uma tendência unilateral, as consequências podem ser notadas em sua aplicação prática. "A colaboração do inconsciente (...) mesmo quando se comporta em oposição à consciência, sua expressão é sempre compensatória de um modo inteligente, como se estivesse tentando recuperar o equilíbrio perdido" ${ }^{16}$. Considerar o ser humano de forma integral envolve compreender que esses aspectos compensatórios do aparelho psíquico são fatores determinantes na conduta de cada pessoa, e que isso implica que na experiência do adoecimento a lógica de vida da pessoa também está expressa. Essa compreensão sem dúvida amplia e por isso mesmo dificulta a do processo de adoecimento e cura, mas abre a possibilidade de entendermos o adoecimento como dimensão não apenas da vida biológica, mas também subjetiva. A partir dessa constatação, a discussão sobre a subjetividade está localizada no próprio processo de conscientização e de visão integral do processo de cura; uma demanda por revisão do plano epistemológico do saber médico e não apenas em sua dimensão ética.

Podemos ainda considerar que "a grande aceitação do conhecimento médico pode ser atribuída a seu significado simbólico, mais que a seu conteúdo"17. A transferência, comumente relacionada ao processo psicoterapêutico, está presente em todos os tipos de relação, marcando a dinâmica estabelecida entre sujeito e objeto, fato este que pode ser modificado mediante trabalho analítico. No caso da prática médica, o confronto com os aspectos deixados em segundo plano inclui a reflexão sobre a escuta, a relação entre médico e paciente, e a presença da subjetividade no adoecimento e na cura. Caso contrário, permanecendo em relações fundadas com base em projeções, o resultado seria o isolamento do sujeito - quer esse sujeito seja reconhecido na figura do médico ou na do paciente. Assim, relações humanizadas só são possíveis a partir do reconhecimento dos complexos inconscientes e das projeções, o que mostra a subjetividade como já inerente tanto à relação médico-paciente, como inclusa nas equações que cada pessoa faz no que diz respeito à sua compreensão da vida e da morte. $\mathrm{O}$ quanto essa dinâmica subjetiva inside no próprio adoecimento e nas condições de cura é algo que ainda merece mais pesquisas.
O fato de o paciente transmitir ao médico um conteúdo ativado do inconsciente também constela neste último o material inconsciente correspondente, através da ação indutiva regularmente exercida em maior ou menor grau pelas projeções. Médico e paciente encontram-se assim numa relação fundada na inconsciência mútua ${ }^{18}$.

Contudo, tal argumento poderia ser considerado como mais uma tentativa falha de implementar uma visão total de cura. Cabe, então, refletir se isto é o suficiente para superar o materialismo ontológico que perpetua a perspectiva de um sujeito fracionado e demonstrar a insuficiência de uma metafísica que tende ao fisicalismo. De posse de um conhecimento objetivo, o médico se sente habilitado para diagnosticar e prescrever; a própria possibilidade de reconhecimento da subjetividade obedece ao mesmo raciocínio. Para o profissional da Psicologia inserido em contexto hospitalar, as demandas de atendimento chegam frequentemente como recurso dos profissionais quando estes encontram dificuldade para gerir a relação com os pacientes, de modo que a subjetividade aparece aqui como dificultador da relação e não como parte do raciocínio terapêutico. Se, por um lado, isso parece indicar a rigidez de um ponto de vista que encontra dificuldades para fazer valer seu plano terapêutico; por outro, mostra também um afeto, a evidência de que já no plano das relações a subjetividade está operando tanto da perspectiva do médico quanto do paciente.

Deste modo, a base da relação médico-paciente não é inteiramente compreendida em todos os seus desdobramentos. Além disso, há uma aparente oposição mantida entre habilidade interpessoal requerida na clínica e o desenvolvimento tecnológico e instrumental que seria primordialmente o elemento principal no processo terapêutico. Nesse sentido, a cura seria buscada através de um imaginário de supressão do fator humano, mesmo que o objetivo final seja a valorização do mesmo. Por outro lado, do mesmo modo como a Medicina toma como suporte principal a naturalização do saber biomédico, o paciente recorre à ciência para fundamentar a confiança que deposita no médico. Quanto menos autonomia o processo de cura relega ao doente, mais ele necessitará de vínculo com o médico e ao conhecimento reproduzido por ele, recorrendo menos a suas próprias conclusões sobre o adoecimento.

O cuidado clínico é teleológico, normativo e moral. Mas o fisicalismo não reconhece propósito ou valor. O materialismo pressupõe a lógica e a matemática; não as explica. Um materialismo eli- 
minativo reduz a consciência a um epifenômeno (...) A Medicina envolve aspectos descritivos e normativos de uma epistemologia fisicalista em uma meta-epistemologia "overachieving" que inclui todos os aspectos presentes na prática clínica sem perceber a insuficiência prática disto ${ }^{19}$.

A prática torna-se reducionista e é no conflito estabelecido entre aspectos humanos e a objetividade clínica que o cuidado clínico pode ser repensado.

\section{Considerações finais}

Vivemos um momento histórico que exige humanização no acolhimento e tratamento, e que insiste na retomada do vínculo nas relações com o paciente. Se as ciências humanas cumprem o necessário papel de criticar o reducionismo mecanicista e o rol de normatizações que são articuladas a partir deste ponto de vista, vemos que este resiste às críticas e em grande medida ainda opera na fundamentação mesma das práticas terapêuticas. Essa peculiaridade de um modelo teórico e institucional que tende à normatização, torna as práticas de atenção à saúde bastante mais complexas e por isso a tarefa de superar os diversos reducionismos que rondam o campo terapêutico exige um esforço de análise crítica de todos os atores e discursos envolvidos, mesmo os de vanguarda. "Quando se trata de discutir os conhecimentos sobre saúde, doença ou sobre os cuidados que visam sublinhar a importância de uma leitura compreensiva, nós somos convidados a conduzir uma reflexão de ordem epistemológica" ${ }^{20}$, o que não implica descuidar das práticas.

Nesses termos, a inclusão da subjetividade, como elemento perturbador da relação terapêutica, é de fundamental importância se a pensarmos também como índice de relativização dos saberes cristalizados nas práticas, contribuindo assim como eixo de análise dos desacordos fundamentais entre teorias e práticas; entre estratégias de bom acolhimento e a forma como esse acolhimento é recebido. Qualquer tentativa de excluir a subjetividade do processo de adoecimento e cura - por descuido ou imposição técnica - mostra-se mal sucedida.

Ao longo do texto, utilizamos o médico apenas como exemplo, tendo em vista que outros profissionais que atuam na prática clínica correm frequentemente o risco de reproduzir, em igual medida, o modelo biomédico. Sendo assim, poderíamos questionar o lugar da subjetivida- de na prática da enfermagem, da psicologia, da nutrição, da fisioterapia, etc. Mas este modelo tem sido duramente criticado principalmente no que tange aos médicos, e nas diretrizes do SUS observamos um movimento que exige uma nova postura coletiva. Esta, no entanto, embora centre suas críticas prioritariamente à medicina, enquanto representante eloquente do modelo biomédico, precisa ser estendida ao conjunto dos profissionais da área de saúde, pois todos estão susceptíveis a construir discursos de exterioridade, mesmo a respeito da subjetividade, o que pode resultar em mudanças no nível retórico que não condizem com a prática. Para avançarmos na reflexão e na efetivação da interdisciplinaridade, um exercício de revisão permanente de teorias e práticas, de todas as áreas envolvidas numa equipe de saúde, faz-se condição necessária. Isso evita que imperativos, sejam eles quais forem, introduzam-se sub-repticiamente numa concepção de saúde que prima pela autonomia e pela responsabilidade social.

Se a Medicina atinge altos níveis de eficácia, apoiada em tantos aparatos tecnológicos de ponta e no aporte do conhecimento científico, não cumpriria dessa forma seu papel, mesmo sem enfatizar os aspectos relacionais da cura? Entendemos que o surgimento dos aspectos subjetivos, na prática cotidiana, cria fissuras espessas o bastante para que a reflexão sistemática sobre os questionamentos trazidos neste ensaio se tornem fundamentais para a revaloração das práticas terapêuticas. Trata-se de uma exigência que vem se construindo com a ampliação mesma dos serviços de saúde, os quais, ao ampliar o escopo do que se entende por atenção à saúde, imprimem a necessidade de repensar teoria e técnica.

Esta fissura ocorre justamente nos interstícios da prática, pois o aparato teórico requer generalizações que não conseguem abarcar a variabilidade implícita nas práticas terapêuticas, a não ser como um tipo de conhecimento com validade menor do ponto de vista técnico. Noutros termos, que a inclusão da subjetividade diria respeito sobretudo a uma dimensão ética, o que não deixa de exprimir, uma vez mais, um aspecto normativo, na medida em que considera a subjetividade apenas a partir da exterioridade. A subjetividade, no entanto, comumente revela a falta de continuidade entre o acontecimento, a vivência prática e as subsequentes tentativas de estabelecer sua correlação com o saber técnico. Ao invés de suprir o fator que complementaria a prática clínica em uma visão do paciente como um todo, a subjetividade corresponde mais à exposição do 
desnivelamento estabelecido entre dois tipos de saberes.

$\mathrm{Na}$ medida em que o saber técnico sobre o adoecimento é mediado pela experiência do sofrimento, a não inclusão deste processo subjacente no corpo teórico do pensamento técnico equivale a deixar escapar uma parte significativa do fenômeno, limitando com isso o acesso ao mesmo. A subjetividade se mostra, pois, como aquilo que resiste, como aquilo que é cerceado por imposições metodológicas ou epistemológicas e por isso não consegue se inscrever no discurso médico (e noutros saberes da área da saúde), embora siga camuflada na prática clínica, independente do contexto. Neste sentido, o desenvolvimento técnico e científico não alcança a amplitude da experiência subjetiva.

Abordar este campo de ação e reflexão através de noções como clínica ampliada, educação permanente, humanização e acolhimento, pode nos dar subsídios para romper com práticas reducionistas, tão abundantes no percurso histórico e epistemológico denunciado até aqui. Sendo assim, partir de um ponto de vista epistemológico não é gratuito, e leva em consideração aspectos práticos. Isso vai no sentido de propor a reestruturação da prática clínica, dentro da qual é preciso conside- rar a fundamental importância da formação dos profissionais, na proposta de equipes interdisciplinares, pautadas em relações horizontais. Não há como questionar o valor de cada uma dessas iniciativas, o que fugiria ao escopo deste ensaio, mas podemos salientar que o modo de pensar a atenção à saúde ainda carece de maior aprofundamento, no sentido de incluir uma revisão de fundo nas práticas, a qual seria grandemente favorecida se agregarmos os desdobramentos estruturais que a inclusão da subjetividade implica.

Mais do que uma lógica de inclusão de aspectos relegados a segundo plano, propomos priorizar estratégias que aproximem ao invés de romper canais de troca e comunicação - tanto no plano epistemológico quanto no mais concreto dia a dia das práticas terapêuticas - incluindo, primordialmente, as condutas de base que sustentam as racionalidades profissionais. Contextualizar a abordagem inicial que visa questionar e revisitar o modelo biomédico e a prática clínica para uma outra abordagem, que perceba as relações e as dinâmicas estabelecidas dentro de um funcionamento específico e de uma nova chave de compreensão. Esse nos parece um direcionamento fundamental para atendermos a proposta de integralidade na atenção à saúde.

\section{Colaboradores}

Os autores ABP Palmeira e RB Gewehr declaram ser responsáveis pela elaboração do manuscrito, tendo ambos contribuído integralmente para a concepção e delineamento do estudo, revisão crítica do conteúdo, elaboração e redação do texto, além da aprovação final da versão a ser publicada. 


\section{Referências}

1. Canguilhem G. O normal e o patológico. $6^{\mathrm{a}} \mathrm{ed}$. Rio de Janeiro: Forense Universitária; 2009.

2. Tesser CD, Luz MT. Racionalidades médicas e integralidade. Cien Saude Colet 2008; 13(1):195-206.

3. Nascimento MC, Barros NF, Nogueira MI, Luz MT. A categoria racionalidade médica e uma nova epistemologia em saúde. Cien Saude Colet 2013; 18(12):35953604.

4. Fonseca AF, Stauffer AB. O processo histórico do trabalho em saúde. Rio de Janeiro: Epsjv/Fiocruz; 2007.

5. Luz MT. Natural, racional, social: razão médica e racionalidade científica moderna. Rio de Janeiro: Campus; 1988.

6. Guerra G. La place de la subjectivité dans le champ de la médecine; 2010. [acessado 2015 Maio 27]. Disponível em: https://www.cairn.info/revue-cliniques-mediterraneennes-2010-2-page-73.htm

7. Zamagni MP. La malattia nella narrazione del medico e del paziente; 2014. [acessado 2015 Maio 26]. Disponível em: http://siba-ese.unisalento.it/index.php/psychofenia/article/viewFile/14678/12798

8. Dunker CIL, Kyrillos Neto F. Sobre a retórica da exclusão: a incidência do discurso ideológico em serviços substitutivos de cuidado a psicóticos. Psicologia: ciência e profissão 2004; 24(1):116-125.

9. Nader AR. Manicômios, prisões e liberdade: entre o pessimismo da razão e o ideal de igualdade. $L a-$ cuna: uma revista de psicanálise 2016; 1:1. [acessado 2015 Maio 27]. Disponível em: https://revistalacuna. com/2016/05/22/manicomios-prisoes-e-liberdade/

10. Nettleton S. The sociology of health \& illness. Cambridge: Polity Press; 1995.

11. Cunningham TV. Objectivity, Scientificity, and the Dualist Epistemology of Medicine; 2015. [acessado 2015 Jun 10]. Disponível em: http://philpapers.org/archive/ CUNOSA-2.pdf

12. Jung CG. A vida simbólica. Petrópolis: Vozes; 2012.
13. Mann T. Der Zauberberg. [acessado 2015 Maio 16]. Disponívelem:https://vk.com/doc143790965_365454849? hash $=3021 \mathrm{a} 57 \mathrm{~d} 579 \mathrm{~d} 1387 \mathrm{~b} 5 \& \mathrm{dl}=\mathrm{cd} 52 \mathrm{~d} 6963 \mathrm{fe} 8 \mathrm{e} 5 \mathrm{~d} 88 \mathrm{c}$

14. Pigeaud J. Folie e cure de la folie chez les médecins de l'antiquité gréco-romaine: La manie. Paris: Les belles lettres; 2010.

15. Jung CG. Practice of Psychotherapy. Princeton: Princeton University Press; 2014.

16. Jung CG. Os arquétipos do inconsciente coletivo. Petrópolis: Vozes; 2000.

17. Young A. The discourse on stress and the reproduction of conventional knowledge. Soc Sci Med Med Anthropol $1980 ; 14 \mathrm{~B}(3): 133-146$.

18. Jung CG. Ab-reação, análise dos sonhos e transferência. Petrópolis: Vozes; 2011.

19. Whatley SD. Borrowed philosophy: bedside physicalism and the need for a sui generis metaphysic of medicine. J Eval Clin Pract 2014; 20(6):961-964.

20. Desgroseilliers V, Vonarx N. Retrouver la complexité du réel dans les approches théoriques de promotion de la santé: transiter par l'identité du sujet. Santé Publique 2014; 26(1):17-31.

Artigo apresentado em 20/12/2015

Aprovado em 16/08/2016

Versão final apresentada em 18/08/2016 